\title{
Ein Ermittler aus Chur
}

Erhard Taverna

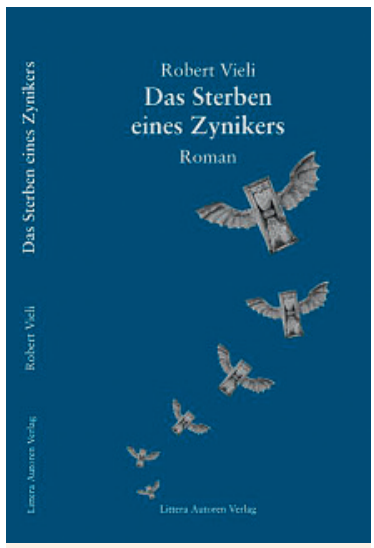

Robert Vieli

Das Sterben

eines Zynikers.

Zürich: Littera Autoren Verlag; 2010.

207 Seiten. Fr. 29.-

ISBN 978-3-906731-34-6

erhard.taverna@saez.ch
Für Robert Vieli, geboren 1935, ist das Schreiben ein Lebenselixier. Als Gymnasiast übte er sich in Gedichten und Theaterstücken, nach der Eröffnung seiner Hausarztpraxis 1969 in Chur entstanden die ersten Kurzgeschichten für die Schweizerische Ärztezeitung. Im Magazin «Med» waren bis zur Einstellung des gediegen aufgemachten Gratisheftes seine Glossen und Kolumnen zu lesen. Diese kennen und schätzen auch die Leser der «Medical Tribune» und des «Bündner Anzeigers» seit langem. War noch ein erstes Buch mit dem Titel «Medizinische Eskalationen» in erster Linie für Freunde und Bekannte gedacht, so wurden seit der 1989 erschienenen Glossensammlung «Wenn Hippokrates das gewusst hätte» sieben weitere Bücher in grösseren Auflagen veröffentlicht.

Robert Vieli hat neben seiner gutgehenden Praxis in jeder freien Minute Geschichten erfunden. An Stoff habe es ihm nie gefehlt, er fand ihn bei der täglichen Arbeit mit Patienten, bei Kollegen, bei Pharmavertretern, auf Kongressen und in der Politik. Wie jeder gute Erzähler schrieb er oft seinen eigenen Einfällen hinterher, Schreiber und Leser in einer Person. Oft stand nicht einmal die Rahmenhandlung fest. Er habe fortlaufend seine Geschichten improvisiert, so dass jede berufliche Unterbrechung, wie zum Beispiel ein Notfall, den weiteren Ablauf spontan beeinflussen konnte.

Wenn ihm ein Romanende allzu geradlinig scheint, denkt er sich eine Überraschung aus, eine fintenreiche Volte, einen allerletzten Dreh, der dann listig für ein kurvenreiches Finale sorgt. Was ihn neben seiner reichen Phantasie auszeichnet, sind Humor und Ironie, ein gutes Gespür, eine unbändige Freude am Flunkern und ein analytischer Scharfsinn, immer mitgetragen von der Liebe zu den realen und fiktiven Figuren. Wenn er mit spitzer Feder die Sünden der Mediziner genüsslich aufspiesst, bleibt er ein exakter Chronist, der das Treiben der Zunft mit Witz und Komik auf den Punkt bringt. Seine Karikaturen sind treffsicher, aber nie böse, sie entlarven, ohne blosszustellen. Zwei Bände vereinigen Glossen. Ein Kriminalroman, «Der Torso im See», erschien 1994, vier Jahre später gefolgt vom Gaunerroman «Ermittlungen in der Provinz».

Häufig sind historische Begebenheiten oder besondere Orte der rhätischen Republik die wahrheitsgetreuen Ausgangspunkte für verschlungene Irrfahrten und sagenhafte Geschichten, etwa in «Der Mann mit dem gläsernen Blick» oder in «Fluch über Malaluna». Aus Kommentaren zu Fotografien in der Zeitung «Südostschweiz» entstand der Bild- und Textband «Gesichter sind Geschichten» in Zusammenarbeit mit dem Fotografen und Pfarrer Hans Domenig.

Seit fast zehn Jahren ist Robert Vieli pensioniert. 2002 erhielt er den gutdotierten Bündner Literatur-

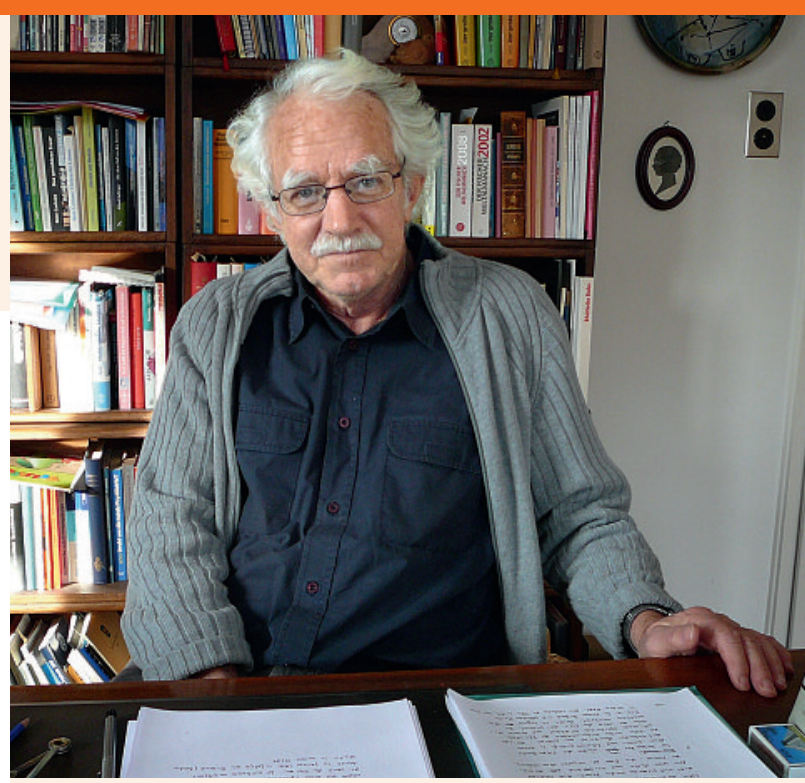

Robert Vieli am «Tatort». Alle Texte schreibt er zweimal von Hand, bevor er sie in den Computer eingibt.

preis der Milly Enderlin Stiftung. Mit Tennis, Langlauf und Fell-Touren hält er sich fit, den Spanischunterricht betrachtet er als «Brain Gym». Aus der massvollen Bewegung kommen die neuen Ideen, zum Beispiel für die bisher unveröffentlichten Kriminalromane mit dem uns noch unbekannten Kommissar Fürbass. Selbst für erprobte Autoren seien Verlage erstaunlich abgeschottete Systeme mit hoffnungslos überforderten Lektoren. Vielleicht wäre es für einen mutigen Verleger an der Zeit, zukünftige Fans mit einer neuen Krimiserie bekanntzumachen. Doch der Autor hat kaum Musse, darüber nachzudenken, denn sobald ein Manuskript, das er zweimal von Hand schreibe, bevor er es in den PC tippe, sich dem Ende nähere, beginne er sofort mit dem nächsten Projekt.

Der vorläufig letzte Roman kommt frisch ab Presse und heisst «Das Sterben eines Zynikers». Darin hält ein todkranker Pharmakologe vom Spitalbett aus Rückschau auf sein sehr bewegtes Leben als Dozent und Unternehmer. Mit Verstand und Whisky hält der Privatpatient seine Umgebung auf Trab, diktiert seiner Ex-Geliebten die Memoiren, empfängt trinkfeste Besucher und sorgt über den Tod hinaus für ein turbulentes Nachspiel. Eine rabenschwarze Komödie, in der niemand ungeschoren davonkommt. Ein Spiel voller Ernst und Galgenhumor, grotesk und abgeklärt, schmerzhaft und weise.

Doch wie könnte es auch anders sein: Die nächste Geschichte hat für den Autor bereits angefangen: Ein pensionierter Polizeikommissar recherchiert nach rätselhaften Anschlägen seine eigene Familienvergangenheit. Wer mehr erfahren möchte, muss sich bis zur nächsten Publikation gedulden. Vorläufig stockt die Handlung, wenn der Blick vom Schreibtisch des Autors über die zugeschneiten Wiesen und Gärten am Rande des Churer Kantonsspitals schweift. Diese sind weiss wie das Schreibpapier, das der flinke Kugelschreiber nach einer kurzen Pause mit einer für einen Arzt erstaunlich leserlichen Schrift wieder Zeile um Zeile vollschreibt. 